\title{
Oportunidades tecnológicas e produção científica: uma análise microrregional para o Brasil $^{* * *}$
}

\begin{abstract}
This paper presents the results of a preliminary research about scientific and industrial activities location in Brazil, using multivariate analysis (cluster analysis). It is suggested that relationships between these activities and the creation of technological opportunities at micro-regional level, could reinforcing both regional and local development.
\end{abstract}

Key words: Spatial economic distribution, technological opportunities, Brazil.

\section{Resumo}

O presente trabalho apresenta os resultados de uma investigação preliminar sobre a localização das atividades científicas e industriais no Brasil, utilizando recursos de análise multivariada (análise de cluster). É sugerido que o relações de interatividade entre estas atividades e a criação de oportunidades tecnológicas ao nível microrregional na economia brasileira, poderia fornecer elementos em favor de estratégias de desenvolvimento econômico regional.

Palavras-chave: distribuição espacial, estrutura produtiva e científico-tecnológica, Brasil. 


\section{Introdução}

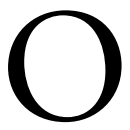

papel da ciência e tecnologia no desenvolvimento econômico tem sido amplamente abordado pela literatura econômica. De um ponto de visa mais geral, o conceito de sistemas de inovação tem contribuído significativamente para o entendimento das relações entre o progresso tecnológico, o avanço científico e o crescimento das economias, locais e nacionais. Neste sentido, pode-se dizer que a construção de uma infraestrutura em ciência e tecnologia, formada não só por centros de pesquisa e universidades, mas também por indústrias e instituições, constituem fator decisivo para o desempenho econômico.

As interações entre as atividades industriais e a produção do conhecimento científico e tecnológico são também fundamentais para o avanço da economia. Quando se pensa nos caminhos que levam da pesquisa básica e desenvolvimento aos benefícios econômicos, deve-se buscar mais as interações possíveis do que as relações determinísticas de causalidade.

O objetivo do presente trabalho é realizar uma investigação preliminar, utilizando recursos de análise multivariada (análise de cluster), sobre a localização das atividades científicas e industriais, tentando sugerir relaçôes de interatividade entre essa última e a criação de oportunidades tecnológicas, tal como definidas em Klevorick et al. (1995), o que poderia fornecer elementos em favor de estratégias de desenvolvimento econômico regional.

$\mathrm{O}$ artigo possui 4 partes fora esta pequena introdução. A segunda seção faz uma breve revisão da literatura visando contextualizar a pesquisa realizada. A metodologia, a base de dados e uma apresentação preliminar dos clusters é apresentada na terceira seção. Na quarta parte são analisados os resultados. No final são apresentadas algumas

\footnotetext{
* Cedeplar/UFMG - Brasil. E-mail: lsilva@cedeplar.ufmg.br

${ }^{* *}$ Cedeplar/UFMG - Brasil. E-mail: limoes@cedeplar.ufmg.br

*** Recibido el 26 de junio de 2003, aprobado el 2 de octubre de 2003
}

considerações finais e sugeridos pontos para a continuidade da pesquisa.

\section{Ciência e tecnologia: interação e causalidades}

A complexidade das relações entre ciência e tecnologia pode ser descrita, na literatura, em termos dos argumentos de dois trabalhos específicos. De um lado, Rosenberg (1982) argumenta em favor da tecnologia como o fator que alavanca o desenvolvimento científico. Por outro lado, o sentido de causalidade é invertido nos trabalhos Klevorick et al. (1995) e Narin et al. (1997). Klevorick et al. discute a criação de oportunidades tecnológicas na interação entre indústrias e universidades, enquanto o trabalho de Narin e colaboradores baseia sua argumentação nas citações de artigos científicos nos registros de patentes depositadas no United States Patent and TradeMark Office (USPTO).

Em particular, os argumentos apresentados em Klevorick et al. são bastante elucidativos. Eles identificam três fontes de oportunidades tecnológicas para os setores industriais. A primeira destas fontes é a pesquisa científica realizada em universidades e centros de pesquisa. As indústrias estariam atentas às atividades realizadas nestes locais, a fim de aproveitar oportunidades de criação e utilização de novas tecnologias. O Quadro 1, a seguir, reproduzido de Klevorick et al. (1995), estabelece quais áreas do conhecimento são mais relevantes para as atividades de setores industriais específicos.

Há no Quadro 1 uma divisão entre o que pode ser denominado de "ciência básica" e "ciência aplicada". No primeiro caso, a "Biologia" está relacionada com o setor de "Drogas e medicamentos"1 (Drugs), entre outros, enquanto "Matemática" e "Física" relacionam-se com os setores de "Instrumentos Óticos" e "Semicondutores", respectiva-

${ }^{1}$ Klevorick et al. (1995) faz esta distinção entre os campos da ciência no corpo do texto. Assim, citam-se as disciplinas "básicas" como : Biologia, Química, Geologia, Matemática e Física. As disciplinas aplicadas são: Ciências Agrárias, Matemática Aplicada, Ciência da Computação, Ciência de Materiais, Ciências Médicas e Metalurgia. Visualmente, as duas categorias estão separadas por um espaçamento maior dentro do Quadro 1. 
Quadro 1. The relevance of science to industrial technology.

\begin{tabular}{|c|c|c|c|}
\hline \multirow[t]{2}{*}{ Science } & \multicolumn{2}{|c|}{$\begin{array}{l}\text { Numbers of industries } \\
\text { with scores: }\end{array}$} & \multirow{2}{*}{$\begin{array}{l}\text { Selected industries in which the } \\
\text { relevance of science to } \\
\text { technological progress was large }\end{array}$} \\
\hline & $>5$ & $>6$ & \\
\hline Biology & 14 & 8 & $\begin{array}{l}\text { Drugs, pesticides, meat products, } \\
\text { animal feed }\end{array}$ \\
\hline Chemistry & 74 & 43 & Pesticides, fertilizers, glass, plastics \\
\hline Geology & 4 & 3 & Fertilizers, pottery, nonferrous metal \\
\hline Mathematics & 30 & 9 & $\begin{array}{l}\text { Optical instruments, machine tools, } \\
\text { motor vehicles }\end{array}$ \\
\hline Physics & 44 & 18 & $\begin{array}{l}\text { Semiconductors, computers, guided } \\
\text { missiles }\end{array}$ \\
\hline Agricultural science & 16 & 9 & $\begin{array}{l}\text { Pesticides, animal feed, fertilizers, food } \\
\text { products }\end{array}$ \\
\hline Applied math/operations research & 32 & 6 & $\begin{array}{l}\text { Guided missiles, aluminum smelting } \\
\text { motor vehicles }\end{array}$ \\
\hline Computer science & 79 & 35 & $\begin{array}{l}\text { Guided missiles, semiconductors, motor } \\
\text { vehicles }\end{array}$ \\
\hline Material science & 99 & 46 & $\begin{array}{l}\text { Primary metals, ball bearings, aircraft } \\
\text { engines }\end{array}$ \\
\hline Medical science & 8 & 5 & $\begin{array}{l}\text { Asbestos, drugs, surgical/medical } \\
\text { instruments }\end{array}$ \\
\hline Metallurgy & 60 & 35 & $\begin{array}{l}\text { Primary metals, aircraft engines, ball } \\
\text { bearing }\end{array}$ \\
\hline
\end{tabular}

Fonte: Klevorick et al. (1995).

mente. Do ponto de vista das disciplinas "aplicadas" encontra-se, por exemplo, a "Ciência da Computação" associada à fabricação de mísseis teleguiados (setor de Amamento Pesado) e veículos automotores.

Neste ponto, são necessárias duas observaçōes sobre a classificação de Klevorick et al.. Primeiramente, Rosenberg (1982) alerta para o caráter artificial, embora possa ser útil, da divisão das pesquisas, de um modo geral, em "pesquisa básica" e "pesquisa aplicada", dado que a linha que separa uma coisa e outra é por demais tênue e de difícil percepção. Isto leva a fazer consideraçōes de mesmo teor no trato das disciplinas científicas e sua separação entre "básica" e "aplicada".

Em segundo lugar, a simples observação do Quadro 1 demonstra que as disciplinas científicas são importantes, e por isso monitoradas, para vários setores industriais e não apenas algum exclusivamente. Isto leva a considerar que as pesquisas e o desenvolvimento científico tem, de fato, maiores impactos nos setores industriais do indica o senso comum de conclusōes imediatistas. Para melhor entendimento, basta considerar que os gastos gerados pela condução de pesquisas em um área científica qualquer pode refletir-se em oportunidades tecnológicas para mais que um setor. Eis ai, o retorno do progresso científico.

A segunda fonte de oportunidades tecnológicas seriam as inovações introduzidas em outras indústrias correlatas e a terceira os feedbacks da própria tecnologia no desenvolvimento científico.

A questão da proximidade entre a produção científica, tecnológica e industrial também é amplamente discutida na literatura. Audretsch \& Feldman (1996) investigam as externalidades do conhecimento e defendem a existências de uma maior propensão a concentrar espacialmente as atividades inovativas para as indústrias onde a pesquisa e desenvolvimento $(\mathrm{P} \& \mathrm{D})$, a pesquisa universitária e o trabalho especializado tivessem maior peso. Em outro artigo, Jaffe et al. (1993) identificam, a partir de patentes e citações, a existência de spillovers geográficos de conhecimento, destacando a importância da proximidade no padrão das citaçôes de patentes e referências.

Recentemente Powell et al. (2002), enfocando o setor de biotecnologia nos Estados Unidos, analisam a aglomeração espacial entre ciência e capital, encon- 
trando padrões de localização conjunta de firmas intensivas em tecnologia e empresas de capital misto financiadoras deste processo, destacando a importância de fatores como tacit knowledge, faceto-face contact e learning process em bases locais e regionais.

Também Albuquerque et al. (2001) discutem esta questão, enfatizando a localização das atividades científicas e tecnológicas em bases municipais no Brasil. Levando em conta o estágio de desenvolvimento do sistema de inovação brasileiro, considerado como um regime imaturo, estes autores encontram uma alta concentração das atividades inovativas no centro-sul do pais, sobretudo no Su- deste, e que esta concentração é maior que a das atividades econômico produtivas, sendo o oposto do caso americano. Através da comparação entre índices de Gini de ciência e tecnologia, o trabalho de Albuquerque et al. conclui que São Paulo possui os menores coeficientes de concentração e maior capacidade de complementaridade com seu entorno.

Complementarmente procuramos destacar a distribuição de setores científicos e industriais de base tecnológica pelas microrregiōes brasileiras, enfatizando as oportunidades tecnológicas potenciais e as aglomeraçóes espaciais a elas relacionadas ${ }^{2}$.

Mapa 1. Distribução espacial da produção cientifica. Brasil -microrregiōes homogêneas.

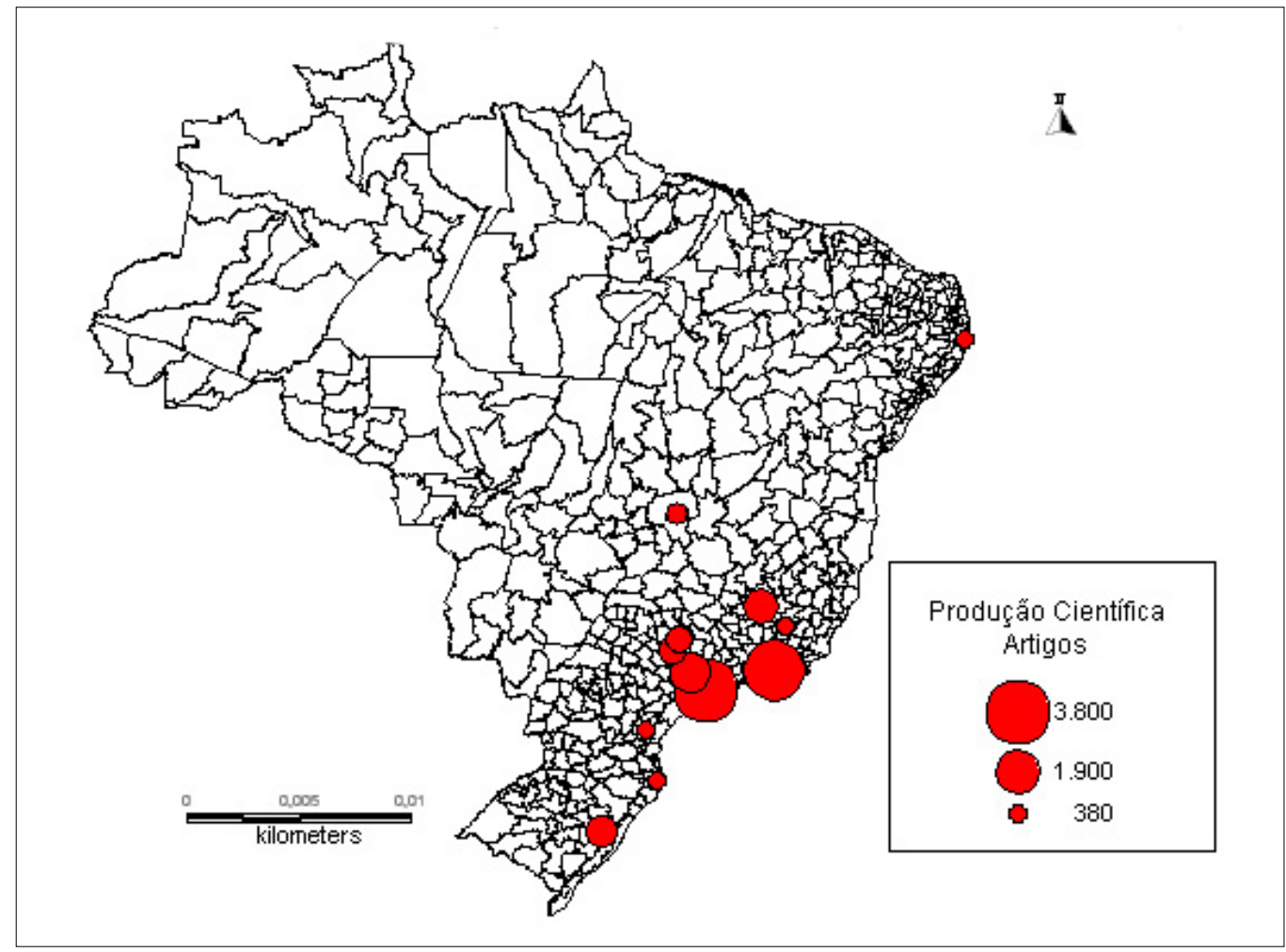

${ }^{2}$ Cabe destacar que, a despeito do importante papel desempenhado pelas instituiçōes (Estado, universidades, institutos de pesquisa, sindicatos patronais e de trabalhadores, agências de regulação e de fomento, bancos, etc.), na configuração espacial da indústria, da ciência e da tecnologia no Brasil -procuramos destacar aqui apenas alguns elementos de uma lógica espacial específica, a saber, a relação entre as oportunidades tecnológicas e os diferenciais de produção científica a nível microrregional brasileiro. Para uma análise do papel das instituiçôes na conformação recente da divisão inter-regional do trabalho no Brasil ver Diniz e Lemos (1997), Diniz e Afonso (1998), Diniz e Gonçalves (2000), Diniz (2001), dentre outros. 
Mapa 2. Distribução espacial do emprego. Setores seleccionados da indústria. Brasil -microrregiões homogêneas.

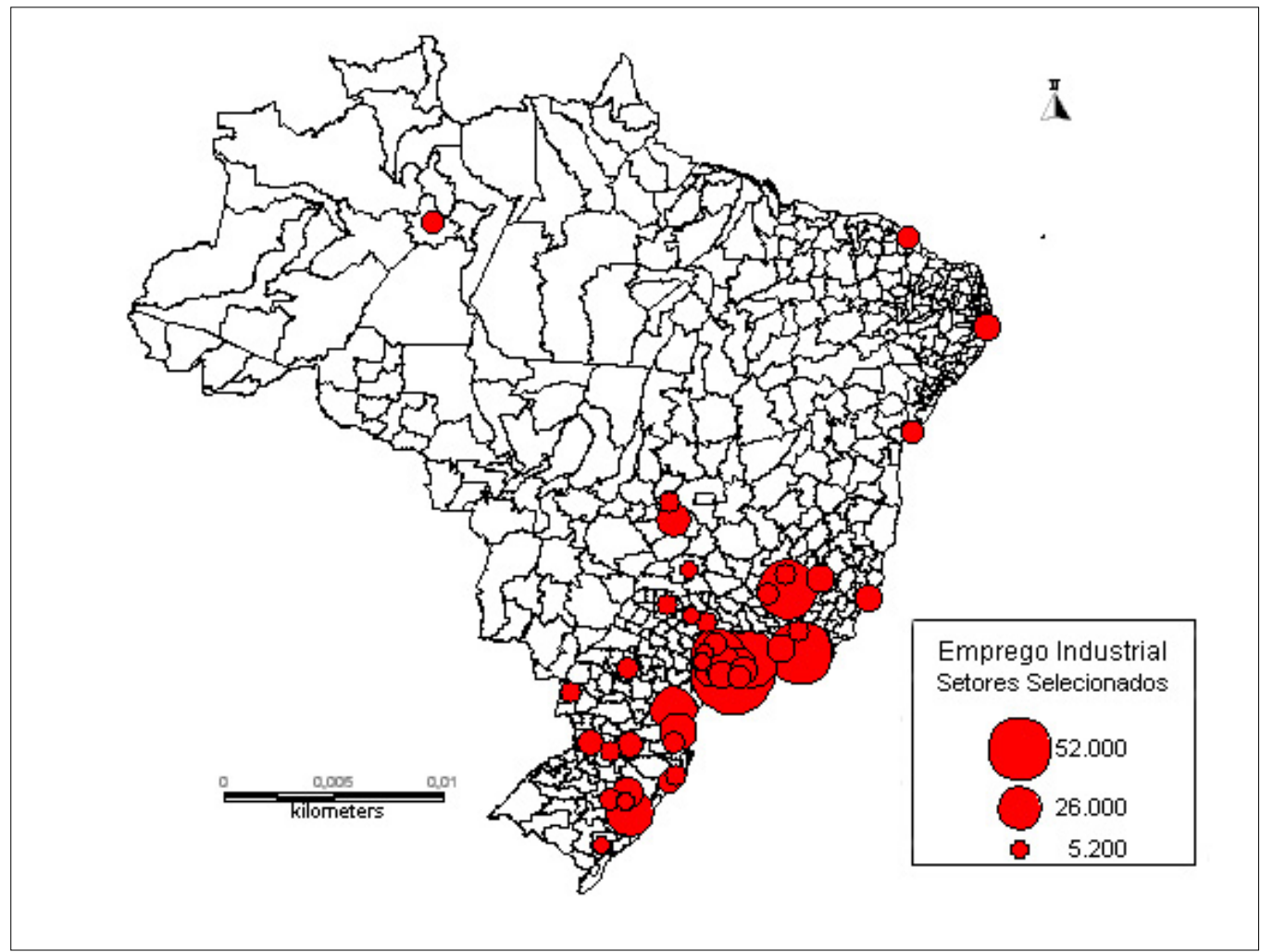

\section{Fontes, metodologia e apresentação dos clusters}

\subsection{As bases de dados}

Este artigo utiliza duas bases de dados principais. A primeira delas é constituída de um banco de dados com artigos científicos (excluindo-se as ciências sociais e artes) ${ }^{3}$ publicados em 1999 , onde ao menos um dos autores apresentou endereço no Brasil. Os dados foram coletados no Institute for Scientific Information, via Internet (ISI, 2001). Desta forma, foi possível proceder à classificação destes artigos por área do conhecimento, a partir da especialização do periódico onde este foi publicado.

\footnotetext{
${ }^{3}$ A despeito da importância, por óbvio, da produção acadêmica da área de ciências sociais e artes optou-se aqui, seguindo Klevorick et al. (1995), pela não inclusão de informaçôes sobre artigos acadêmicos das áreas de ciências sociais e artes. Isto baseia-se no fato de que a vinculação entre oportunidades tecnológicas e produção científica das áreas sociais e artes é de difícil percepção e de mensuração indireta e contra-intuitiva.
}

A atribuição de um município como local de origem de cada artigo, foi feita utilizando-se as referências de endereço dos autores. Assim, os artigos em co-autoria cujos autores eram de municípios diferentes foram contados uma vez para cada cidade. O Mapa 1 nos fornece esta distribuição por microrregiōes, e nos permite visualizar a concentração da produção científica brasileira em poucas localidades, precipuamente as sedes das principais universidades públicas federais, e estaduais no caso paulista, do país.

A segunda base de dados utilizada é o Relatório Anual de Informaçôes Sociais 2000 (RAIS, 2000), do Ministério do Trabalho e Emprego. Esta base forneceu o numero de empregados utilizados nos setores industriais brasileiros por município e classe CNAE (Classificação Nacional de Atividade Econômica) em 2000, tomadas como proxy da escala industrial nos municípios. 
Quadro 2. Adaptação do Quadro 1 para áreas do conhecimento CNPq e Classificação CNAE.

\begin{tabular}{|l|l|}
\hline \multicolumn{1}{|c|}{ Ciência } & \multicolumn{1}{c|}{ Setores industriais } \\
\hline Biologia & $\begin{array}{l}\text { Drogas e medicamentos, pesticidas, } \\
\text { produtos de carne, comida animal }\end{array}$ \\
\hline Química & Pesticidas, fertilizantes, vidro, plástico \\
\hline Geologia & Fertilizantes, cerâmica, metais não ferrosos \\
\hline Matemática & Instrumentos óticos, máquinas-ferramenta, automóveis \\
\hline Física & Eletrônico básico, computadores, armamento pesado \\
\hline Ciências Agrárias & Pesticidas, comida animal, fertilizantes, alimentos \\
\hline Matemática/estatística aplicada & Armamento pesado, alumínio automóveis \\
\hline Ciência da Computação & Armamento pesado, eletrônico básico, automóveis \\
\hline Ciências Médicas & $\begin{array}{l}\text { Drogas e medicamentos, instrumentos } \\
\text { médico-cirúrgicos }\end{array}$ \\
\hline Ciência de Materiais e Metalurgia & Metais primários, aeronaves, \\
\hline
\end{tabular}

Fonte: Klevorick et al. (1995), elaboração própria.

\subsection{Tratamento dos dados}

Os dados originais sobre artigos e empregados na indústria sofreram dois tratamentos principais antes de serem analisados. O primeiro foi a agregação das mesmas de maneira a torná-los análogos às categorias apresentadas por Klevorick et al. (1995), fazendo com que os artigos científicos tivessem suas áreas do conhecimento adaptadas para tornarem-se compatíveis. Neste mesmo sentido, os dados sobre os setores industriais foram re-arranjados, a partir das classes $\mathrm{CNAE}$, para que correspondessem à mesma estrutura (Quadro 1). Os resultados desta reformulação dos indicadores são apresentados no Quadro 2, a seguir. Por sua vez o Mapa 2 nos mostra a distribuição espacial de tais setores pelas microrregiōes brasileiras, corroborando a conhecida concentração da atividade produtiva no país.

Tanto artigos quanto empregados industriais, que inicialmente se encontravam distribuídos em municípios, sofreram uma nova agregação para que pudessem ser analisados por microrregiōes do Instituo Brasileiro de Geografia e Estatística (IBGE). Estas microrregiōes é que constituem a unidade de análise deste trabalho. Isto foi feito na tentativa de reduzir a desconexão entre os municípios quanto à produção científica e outros indicadores econômicos, tal como alertado por Albuquerque et al. (2001).

Por fim, as variáveis não foram tomadas em nível, mas na sua participação relativa no total do país para cada microrregião. Este procedimento visou uniformizar a escala em que em que as variáveis foram utilizadas.
A partir deste arranjo, procedemos o cálculo de clusters de microrregióes segundo cada conjunto de atributos, ou seja, agrupamos as microrregiōes observando sua concentração relativa em cada uma das áreas de conhecimento e especialização setorial produtiva. Para tanto, utilizamos o método hierárquico aglomerativo com distâncias euclidianas no chamado procedimento de Ward ${ }^{4}$. Este método de análise multivariada tem por característica agrupar elementos de modo a minimizar as diferenças (distâncias) intra-aglomerados e maximizar as diferenças inter-grupos. Deste modo indivíduos (no nosso caso as microrregiōes) com características análogas tendem a se aglomerar em clusters específicos com níveis variados, e mensuráveis relativamente, de unidade interna.

\subsection{Apresentação dos clusters}

Os dados foram analisados em três etapas. $\mathrm{Na}$ primeira calculou-se uma matriz de correlaçōes entre as variáveis apresentadas no Quadro 2. A maioria das variáveis apresentou alta correlação, pelo menos com uma outra variável, de forma que, aquelas cuja correlação máxima foi inferior a 0,8 não entraram nas etapas seguintes 5 .

Em uma segunda etapa, agruparam-se os dados remanescentes da primeira etapa, devidamente normalizados, em clusters hierárquicos por variáveis

${ }^{4}$ Como é uma metodologia amplamente difundida e conhecida não iremos aqui especifica-la. Ver Mainly (1986), dentre outros.

${ }^{5}$ As variáveis que permaneceram na análise apresentaram correlações superiores a 0,89 . 
Quadro 3. Distribução dos cluster.

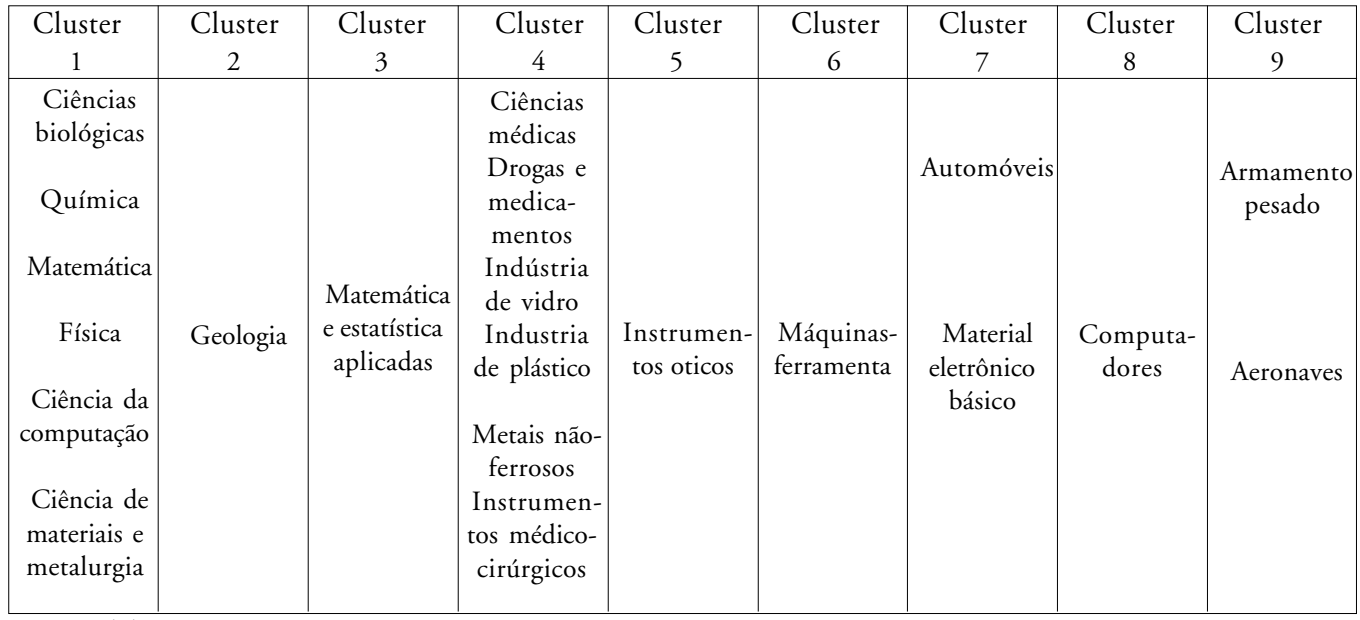

Fonte: elaboração própria.

utilizando o quadrado das distâncias euclidianas e o método entre-grupos. Por fim, o resultado desta etapa é apresentado no Quadro 3, no qual os grupos são formados pelas variáveis que apresentam uma distribuição semelhante entre as microrregiōes.

O primeiro cluster apresentado no Quadro 3 revela que as áreas do conhecimento formam um grupo entre si, i.e., possuem uma distribuiçãao semelhante no espaço. Assim, pode-se dizer que as localidades, no nosso caso microrregióes, que têm uma alta produção científica (medida por artigos) em uma determinada área, em geral, terá uma produção semelhante nas demais disciplinas. Os clusters 2 e 3 mostram que as áreas da geologia e matemática e estatística aplicadas apresentam uma distribuição diferente das demais disciplinas.

O quarto cluster é o mais interessante para os propósitos deste trabalho. Tem-se agrupados os setores de drogas e medicamentos, instrumentos médico-cirúrgicos e ciências médicas, revelando uma possível capacidade de atração da ciência em direção à indústria na construção de oportunidades tecnológicas. Além disso, o cluster 4 reúne outros setores industriais que, embora não estejam diretamente relacionados às oportunidades tecnológicas ligadas à produção de conhecimento científico, mostram sentido econômico na sua distribuição espacial semelhante.

Os dois grupos seguintes, quinto e sexto clusters, correspondem aos setores de instrumentos óticos e máquinas ferramentas, respectivamente. Seria esperado que estes estivessem junto às atividades científicas na área matemática, como sugerido no Quadro 2. Contudo, estes setores apresentam uma distribuição própria, não apenas independentes das áreas da ciência, como também entre si.

O cluster 7, agrupa os setores automobilístico e eletrônico. Mais uma vez, não é verificada a influência específica da produção científica na localização desta atividade, porém, permanece o sentido econômico no fato deste dois setores estarem associados no espaço, uma vez que a indústria de automóveis é grande demandante de material eletrônico, e o desenvolvimento do Brasil neste último setor não é suficiente para organizar indústrias mais tecnologicamente sofisticadas como a de computadores, por exemplo.

Desta forma, a indústria de computadores compõem um grupo próprio, separadamente do desenvolvimento científico na área da computação e da fabricação de material eletrônico. De fato, como foi mostrado anteriormente, a ciência da computação é atraída muito mais pelo desenvolvimento de outras áreas da ciência correlatas como física e matemática. Olhando por um outro ângulo, a ausência de uma indústria de componentes eletrônicos suficientemente desenvolvida justifica o descolamento do setor de computadores do setor de material eletrônico. A lógica da localização neste caso, pode-se dizer, não reflete os aspectos relacionados às oportunidades tecnoló- 
gicas, mas a outros fatores aglomerativos, tais como um mercado de trabalho especializado, incentivos fiscais em variados níveis dentre outros.

Por último, o fato do setor de armamento pesado e de aeronaves estar em um cluster separado, não associados às áreas do conhecimento, pode ser explicado por determinações até mesmo geo-políticas e sócio-históricas, dado que, como será mostrado mais tarde, estes setores encontram-se concentrados espacialmente. Em complemento, a associação entre estes dois setores em um único grupo também pode estar relacionada à questôes estratégicas e econômicas, no sentido que o setor de aeronaves demanda fatores do setor de armamento na parcela da produção destinada ao setor militar.

O passo seguinte da análise consiste em agrupar, com os mesmos dados e métodos, as microrregióes em clusters a partir dos resultados da etapa anterior.

\section{Análise dos resultados}

Os agrupamentos encontrados anteriormente em termos das variáveis, foram utilizados no sentido de verificar em quais regiōes estão localizados os clusters do Quadro 3.

Os resultados encontrados utilizando-se as variáveis do cluster 1 são sumarizados no dendograma da Figura 1 e na Tabela 1. A primeira observação a ser feita é quanto a existência de dois grupos bem distintos. No primeiro grupo, estão as microrregióes que apresentam um alto nível de produção científica nestas áreas específicas. Estas localidades são responsáveis, individualmente, por médias superiores a $10 \%$ do total dos artigos publicados. A soma das participações médias de cada região dá ao grupo, como um todo, uma parcela de $48 \%$ da produção de artigos nestas áreas. Dentro deste primeiro grupo deve-se destacar a região do Rio de Janeiro com uma média de $21 \%$ do total, sendo suas maiores contribuições nas áreas da matemática $(30,67 \%)$, física $(24,08 \%)$ e ciência da computação $(24,92 \%)$, sendo muito superior às demais microrregiōes. Com médias mais baixas, aproximadamente metade dos valores encontrados para a microrregião do Rio de Janeiro, destacamse as micro de São Paulo e Campinas com 14,94\% e $11,80 \%$, respectivamente, da produção de artigos nas áreas do conhecimento relativos ao cluster 1 . São Paulo destaca-se pelo peso das disciplinas Física e Biologia, enquanto Campinas pelo importância das áreas de Química e Matemática.

O terceiro cluster bem definido deve, por sua vez, ser subdividido em outros três grupos. Inicialmente, surge a região de São Carlos/SP, com uma participação média de $6,72 \%$, o que, por um lado, a separa das regióes dos dois primeiros grandes clusters. Por outro lado, é a alta participação nas áreas de química (11,58\%), física $(8,36 \%)$ e ciência da computação $(8,94 \%)$ que a distingue das demais regiōes.

Em seguida, aparece o cluster formado por Florianópolis, São José dos Campos, Porto Alegre e Belo Horizonte. A contribuição média total deste grupo para a produção científica do Brasil nestas áreas é de $14,45 \%$. O destaque, desta vez, fica com Belo Horizonte nas áreas de biologia $(6,88 \%)$ e ciência de materiais e metalurgia $(6,55 \%)$. Porto Alegre destaca-se por sua participação em física $(5,04 \%)$ e ciência da computação $(5,11 \%)$. O terceiro subgrupo é formado pelas demais regióes, que possuem uma média de apenas $(0,05 \%)$ do total, com destaque para Brasília com uma média de $2,74 \%$ e uma participação de $6,97 \%$ em física.

Quanto ao cluster correspondente a área da geologia, os resultados estão apresentados na Figura 2 e na Tabela 2. Novamente, surgem dois agrupamentos distintos. O Primeiro, formado por São Paulo, Rio de Janeiro e São José dos Campos, é responsável por mais da metade da produção científica nesta disciplina. Sobretudo São Paulo se destaca neste subgrupo por contribuir com um quarto das publicações no país (ver TAB 2). O segundo agrupamento também é relacionado na Tabela 2 . Neste caso, há um número maior de regiōes que são responsáveis por aproximadamente $30 \%$ da área de conhecimento. Esta alta concentração nestes dois agrupamentos principais, e em particular em São Paulo, pode ser considerada a razão pela qual esta disciplina não aparece junto às demais (Quadro 2), ou junto a um dos setores correspondentes no Quadro 2. As demais microrregiōes constituem um terceiro e menos relevante cluster com uma contribuição conjunta de $20,15 \%$ e uma média de $0,03 \%$ dos artigos. 
Figura 1. Dendograma utilizando Cluster 1 -Áreas do conhecimento (Quadro 1).

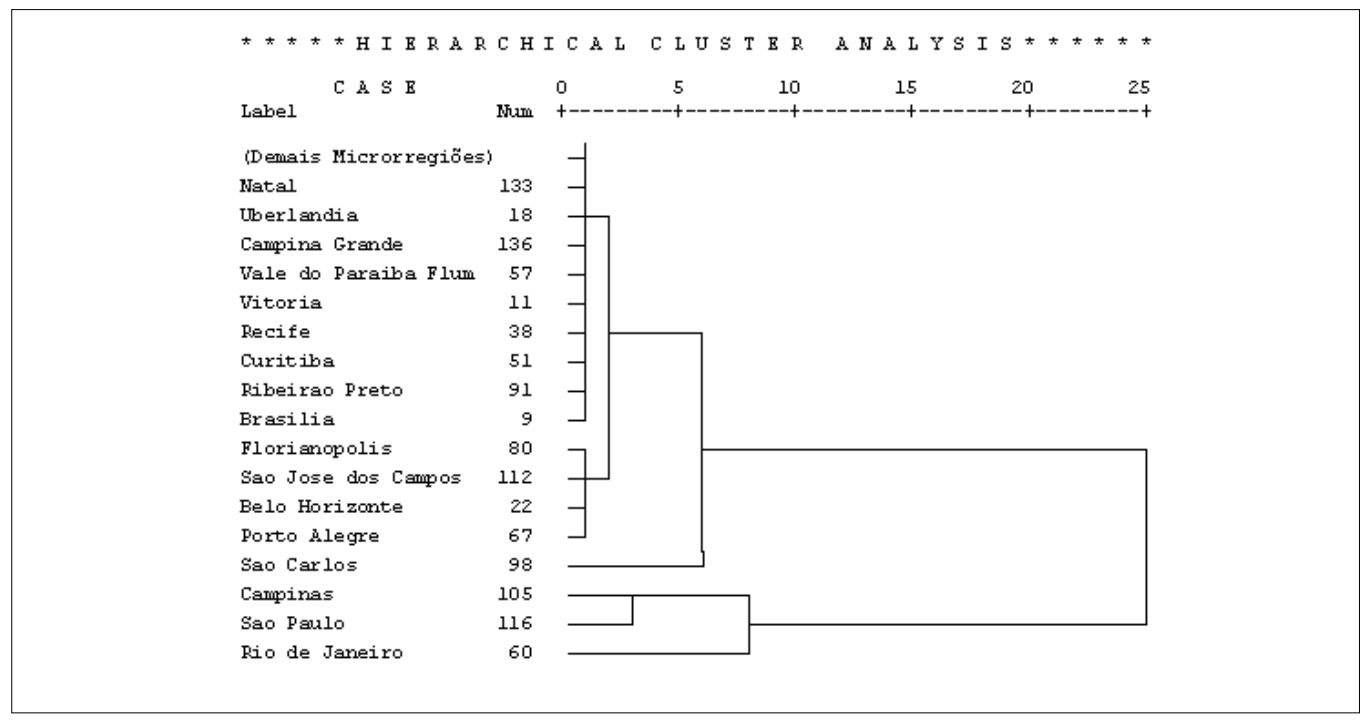

Fonte: Saída do pacote SPSS versão 10.

Figura 2. Dendograma utilizando Cluster 2-Geologia (Quadro 1).

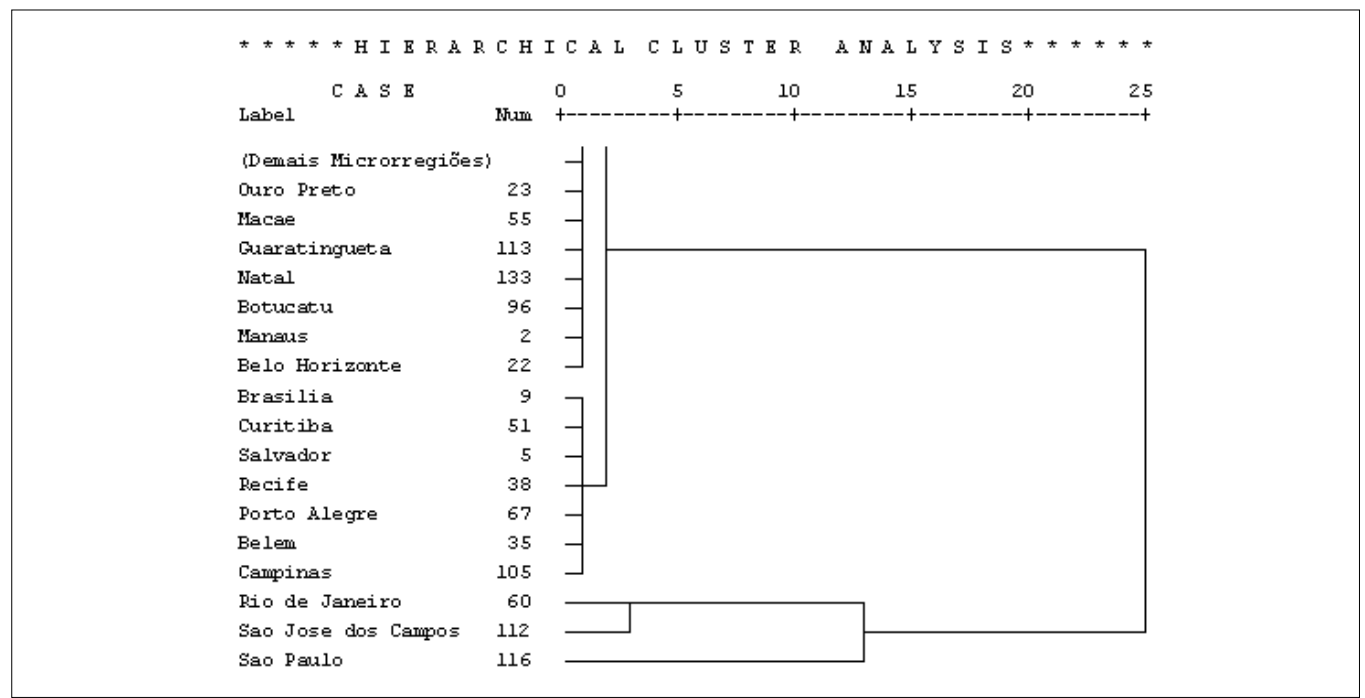

Fonte: Saída do pacote SPSS versão 10.

O cluster referente à área de matemática/estatística aplicada é mostrado no dendograma da Figura 3. São Paulo constitui um cluster isolado e tem uma participação de 36,84\% do total, enquanto Belo Horizonte, Recife e São Carlos formam um segundo grupo com $15,78 \%, 13,15 \%$ e $10,52 \%$, respectivamente (Tabela 3). Estes dois agrupamentos correspondem conjuntamente por $76,31 \%$ dos artigos publicados nesta área, sendo que, os restantes 23,69\% corresponde ao terceiro grupo, formado pelas demais regióes. $\mathrm{O}$ destaque dentro deste último agrupamento são as microrregióes de Piracicaba e Campinas, que mesmo não se constituindo um cluster separado contribuem com 5,26\% cada uma. 
Tabela 1. Distribuição da produção científica por microrregião e área do conhecimento -Brasil 1999, em porcentagem.

\begin{tabular}{|l|l|c|c|c|c|c|c|c|c|}
\hline UF & \multicolumn{1}{|c|}{ Microrregião } & Biologia & Química & Matemática & Física & $\begin{array}{c}\text { Ciência da } \\
\text { computação }\end{array}$ & $\begin{array}{c}\text { Ciência de } \\
\text { materiais/ } \\
\text { metalurgia }\end{array}$ & Média & $\begin{array}{c}\text { Desvio } \\
\text { padrão }\end{array}$ \\
\hline RJ & Rio de Janeiro & 18,91 & 12,40 & 30,67 & 24,08 & 24,92 & 16,66 & 21,27 & 6,55 \\
\hline SP & Campinas & 7,88 & 15,55 & 13,74 & 10,77 & 12,46 & 10,38 & 11,80 & 2,7095 \\
\hline SP & São Paulo & 16,00 & 13,31 & 14,14 & 19,88 & 13,73 & 12,56 & 14,94 & 2,67 \\
\hline & SOMA & 42,81 & 41,27 & 58,56 & 54,74 & 51,11 & 39,61 & 48,02 & \\
\hline SP & São Carlos & 1,76 & 11,58 & 5,57 & 8,36 & 8,94 & 4,09 & 6,72 & 3,58 \\
\hline MG & Belo Horizonte & 6,88 & 4,69 & 4,78 & 3,79 & 2,23 & 6,55 & 4,82 & 1,73 \\
\hline RS & Porto Alegre & 3,50 & 4,26 & 4,78 & 5,04 & 5,11 & 4,09 & 4,46 & 0,62 \\
\hline SC & Florianopolis & 2,10 & 3,40 & 0,59 & 2,36 & 3,83 & 5,46 & 2,96 & 1,66 \\
\hline SP & São Jose dos Campos & 0,13 & 1,07 & 0,59 & 2,00 & 2,23 & 7,37 & 2,23 & 2,64 \\
\hline & SOMA & 12,63 & 13,44 & 10,75 & 13,21 & 13,41 & 23,49 & 14,49 & 4,52 \\
\hline
\end{tabular}

Fonte: ISI (1999), elaboração própria.

Tabela 2. Distribuição da produção científica em geologia por microrregião -Brasil 1999, em porcentagem.

\begin{tabular}{|l|l|r|}
\hline \multicolumn{1}{|c|}{ UF } & \multicolumn{1}{|c|}{ Microrregião } & Geologia \\
\hline RJ & Rio de Janeiro & 15.82 \\
\hline SP & São Jose dos Campos & 10.20 \\
\hline SP & São Paulo & 25.77 \\
\hline & Soma & 51.79 \\
\hline & Média & 17.26 \\
\hline & Desvio padrão & 7.88 \\
\hline BA & Salvador & 3.32 \\
\hline DF & Brasília & 2.81 \\
\hline PA & Belém & 4.85 \\
\hline PE & Recife & 5.10 \\
\hline PR & Curitiba & 2.81 \\
\hline RS & Porto Alegre & 5.10 \\
\hline SP & Campinas & 4.08 \\
\hline & Soma & 28.06 \\
\hline & Média & 4.01 \\
\hline & Desvio padrão & 1.03847 \\
\hline
\end{tabular}

Fonte: ISI (1999), elaboração própria.

O quarto cluster do Quadro 3 é o mais interessante em termos das oportunidades tecnológicas. Do ponto de vista das microrregiōes, São Paulo encontra-se isolada em um dos grupos, como mostra a Figura 4, com uma participação de $34,36 \%$ em ciências médicas e uma média de $28,25 \%$ dos setores industriais. Em seguida, a microrregião do Rio de Janeiro apresenta uma média de $8,42 \%$ nas indústrias e $14,01 \%$ na produção científica, constituindo um outro cluster (Tabela 4).

É necessário que sejam feitas algumas observaçōes em relação a este cluster. Em primeiro lugar, a participação da microrregião de São Paulo naquelas atividades é bastante alta, revelando a importância e a contribuição desta regiāo para a criação de oportu- nidades tecnológicas no país, tendo em vista a relação entre a produção científica e atividades industriais, sugerida anteriormente.

Em segundo, o cluster 4 do Quadro 3 apresenta duas lógicas de agrupamento. A primeira delas é a tecnológica, representada pela presença dos setores de drogas e medicamentos e instrumentos médicocirúrgicos e de atividades na área de ciências médicas. Uma segunda orientação para a formação deste agrupamento é a econômica. A presença dos setores de vidro, plástico e metais não ferrosos sugere um encadeamento produtivo na medida em que se associam com o setor de drogas e medicamentos e de instrumentos médico-cirúrgicos, na área de embalagens. Além do mais, a presença de outras 
Figura 3. Dendograma utilizando Cluster 3 - Matemática/estatística aplicada (Quadro 1).

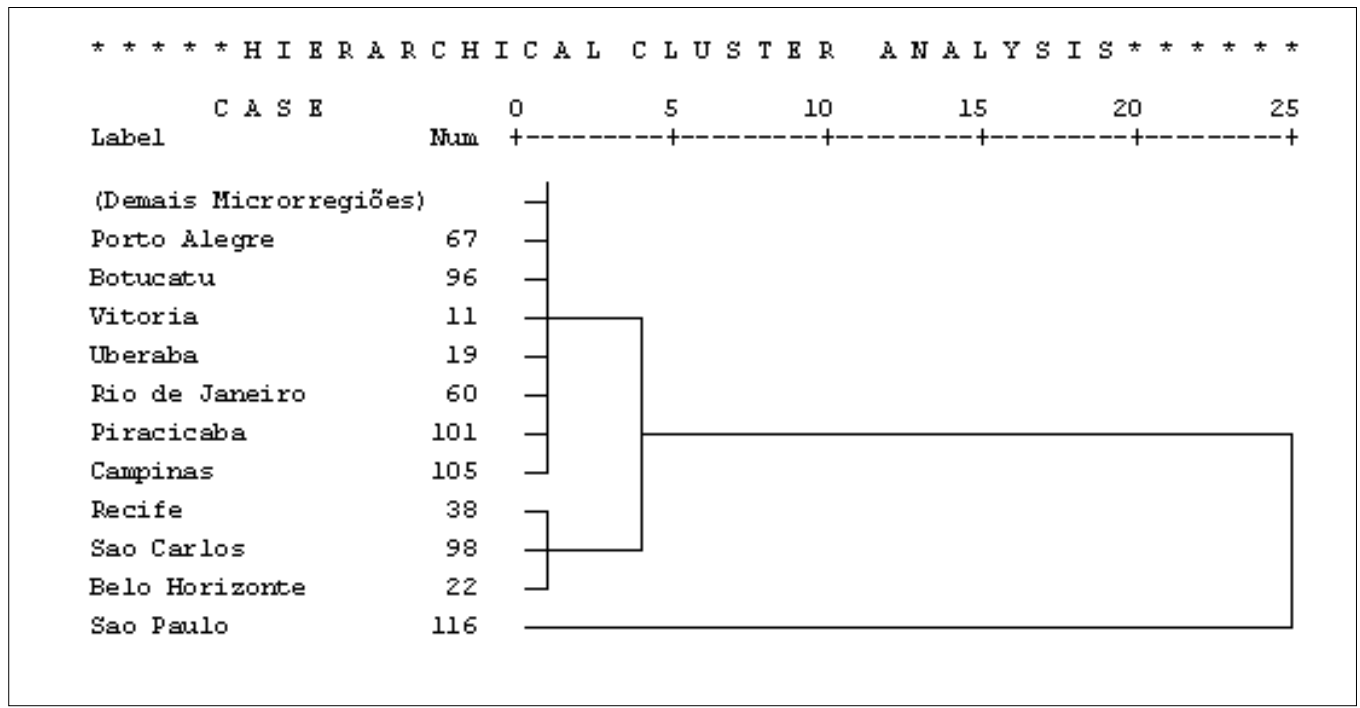

Fonte: Saída do pacote SPSS versão 10.

Figura 4. Dendograma utilizando Cluster 4 -Ciências médicas e setores selecionados (Quadro 1).

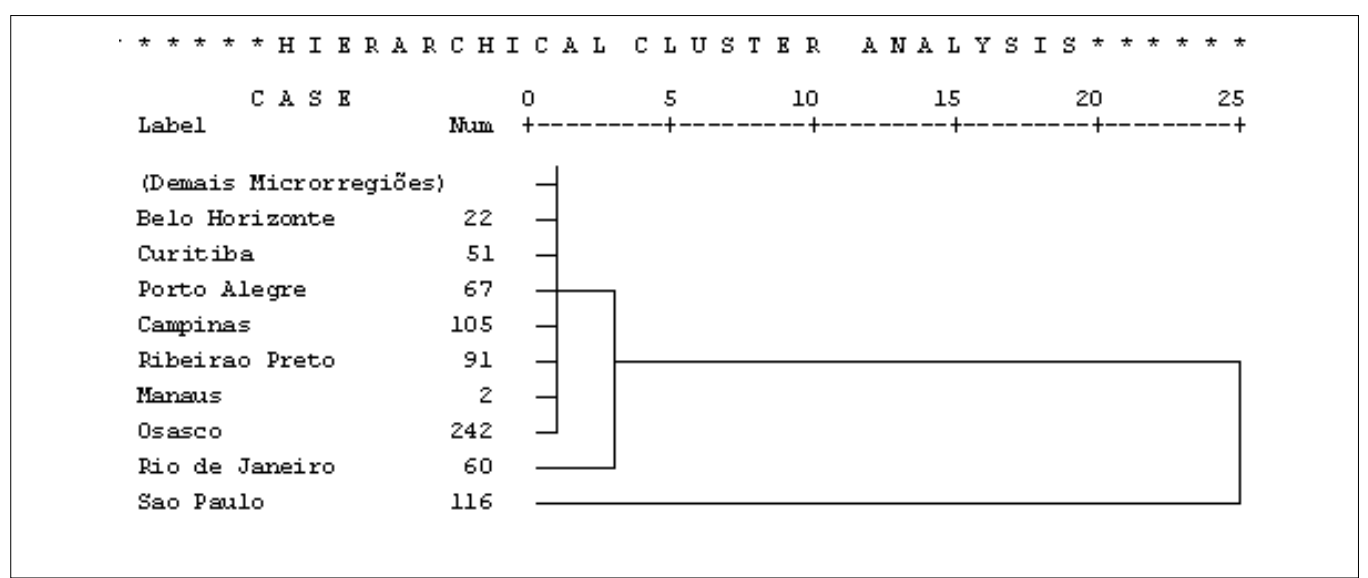

Fonte: Saída do pacote SPSS versão 10.

indústrias pode constituir uma fonte de oportunidades tecnológicas, dada a existência de fluxos tecnológicos intra e interfirmas (Pavitt, 1984).

Desta forma, deve-se atentar para as demais microrregiōes da Tabela 4. Embora estas apresentem valores menores em relação às duas primeiras, sua distribuição, em termos da contribuição em cada área, demonstra a existência das duas lógicas mencionadas, sobretudo a tecnológica.
As microrregiōes correspondentes ao cluster 5 (Quadro 3), estão apresentadas na Figura 5 e Tabela 5. Inicialmente existem dois agrupamentos. No primeiro encontram-se as regiōes de São Paulo e Campinas, em um nível superior, seguidas pela microrregião do Rio de Janeiro, que somada às duas primeiras correspondem a quase metade do setor. Um outro agrupamento, de ordem mais baixa, pode ser observado. Estas outras microrregiões, explicitadas na Tabela 5, com destaque para as 
Tabela 3. Distribuição da produção científica em Matemática/estatística aplicada por microrregião - Brasil 1999 , em porcentagem.

\begin{tabular}{|c|l|c|}
\hline UF & \multicolumn{1}{|c|}{ Microrregião } & $\begin{array}{c}\text { Matemática/ } \\
\text { estatística aplicada }\end{array}$ \\
\hline SP & São Paulo & 36.84 \\
\hline MG & Belo Horizonte & 15.78 \\
\hline PE & Recife & 13.15 \\
\hline SP & São Carlos & 10.52 \\
\hline & Soma & 39.47 \\
\hline & Média & 19.73 \\
\hline & Desvio padrão & 2.63 \\
\hline
\end{tabular}

Fonte: ISI (1999), elaboração própria.

microrregiōes de Manaus, Osasco e Porto Alegre, representam $35,98 \%$ do total do setor que, em conjunto com o primeiro agrupamento, representam mais de $80 \%$ do total.

A industria de máquinas-ferramenta tem a distribuição como representada na Figura 6 e Tabela 6. São dois os agrupamentos principais. O primeiro reúne as microrregiôes de São Paulo e Campinas, com um total de $42,56 \%$ dos empregados no setor, enquanto Porto Alegre, Limeira e Sorocaba são responsáveis por outros $25,53 \%$. A importância destas ultimas só faz corroborar a expansão da indústria de conteúdo tecnológico naquilo denominado por Diniz (1994) de "polígono do desenvolvimento brasileiro", especificamente destacando o hinterland da Região Metropolitana de São Paulo.

A Figura 7, mostra o dendograma para o cluster de automóveis e material eletrônico. São Paulo e São José dos Campos respondem por 67,91\% dos empregados no setor de automóveis e 45,42\% do setor de material eletrônico. Em um segundo grupo, Belo Horizonte e Curitiba, apesar da baixa participação em material eletrônico, juntas somam apenas 5,34\%, possuem $22,82 \%$ dos empregados na indústria de automóveis. Obviamente que a existência de montadoras nestas microrregiōes explica esta configuração. O que podemos destacar de interessante é a pouca integração em Belo Horizonte e Curitiba deste setor com o de eletrônicos, precipuamente eletrônica embarcada. Em relação às demais microrregiōes, vale observar a participação de Manaus, Porto Alegre, Campinas e Recife, no setor de material eletrônico com uma média de $5,83 \%$, porém com baixa participação no setor automobilístico, $0,68 \%$ em média.

Das microrregiōes que compóem o cluster da indústria de computadores, devem ser destacadas São Paulo em um primeiro grupo (33,39\%), Manaus e Osasco em um segundo agrupamento (25,07\%) (ver Figura 8 e Tabela 8). Em relação às outras microrregiōes, o destaque é para o conjunto das microrregiōes de Rio de Janeiro, Campinas, Porto Alegre, Belo Horizonte e Curitiba, somando 29,49\%, com uma média de 5,89\%.

O cluster formado pelo setor de armamento pesado e aeronaves, está descrito na Figura 9 e Tabela

Tabela 4. Distribuição da produção científica por microrregião, disciplina (1999) e setores industriais selecionados (2000), em porcentagem.

\begin{tabular}{|l|c|c|c|c|c|c|c|}
\hline UF & Microrregião & $\begin{array}{c}\text { Ciências } \\
\text { médicas }\end{array}$ & $\begin{array}{c}\text { Drogas e } \\
\text { medicamentos }\end{array}$ & Vidro & Plástico & $\begin{array}{c}\text { Metais } \\
\text { não ferrosos }\end{array}$ & $\begin{array}{c}\text { Instrumentos } \\
\text { médico- } \\
\text { cirúrgicos }\end{array}$ \\
\hline SP & São Paulo & 34,26 & 27,46 & 37,76 & 21,76 & 30,02 & 24,23 \\
\hline RJ & Rio de Janeiro & 14,01 & 15,84 & 9,54 & 6,08 & 2,74 & 7,89 \\
\hline MG & Belo Horizonte & 7,38 & 3,10 & 0,94 & 3,01 & 1,75 & 5,01 \\
\hline SP & Ribeirão Preto & 7,12 & 1,19 & 0,08 & 0,71 & 0,26 & 8,25 \\
\hline RS & Porto Alegre & 8,44 & 1,98 & 4,22 & 5,90 & 3,63 & 3,49 \\
\hline SP & Campinas & 5,04 & 6,75 & 2,70 & 3,17 & 3,59 & 1,92 \\
\hline SP & Guarulhos & 0,07 & 5,79 & 4,28 & 3,60 & 3,28 & 1,20 \\
\hline
\end{tabular}

Fonte: ISI (1999), RAIS (2000), elaboração própria. 
9. São José dos Campos concentra $66,04 \%$ das atividades na primeira indústria e $85,30 \%$ na segunda, formando um grupo. Outro grupo é formado por Juiz de Fora, com 26,29\% do setor de armamento, embora não possua indústria de aeronaves.

Um sumário, portanto, dos resultados é mostrado no Mapa 3. As microrregiōes, bem como o número de clusters em que estas aparecem podem ser visualmente identificadas.

Os dados apresentados até aqui permitem algumas observaçôes interessantes. A primeira delas é quanto a existência de uma especialização científica descolada das atividades industriais relacionadas (de acordo com o Quadro 2) em algumas microrregiōes, com por exemplo as regiões de São Carlos ( Tabela 1 e 3), Recife (Tabela 2 e 3) e Florianópolis (Tabela 1), que aparecem nos clusters relativos às áreas do conhecimento, mas não tem peso nas atividades industriais.

Este resultado, reflete dois pontos principais. $\mathrm{O}$ primeiro, é a existência de lacunas na cadeia produtiva, no sentido de oferecer produtos e serviços capazes de complementar a produção científica destas regiôes na atração dos setores industriais inter-relacionados, e assim, proporcionar a criação e aproveitamento de oportunidades tecnológicas. $\mathrm{O}$ segundo ponto é a possibilidade de complementaridade entre regiôes especializadas em conhecimento e o seu entorno produtivo, em conformidade com os resultados apresentados por Albuquerque et al. (2001). De fato, a existência de uma capacidade científica relativamente pouco explorada, constitui uma possibilidade de desenvolvimento regional, na medida em que pontos vulneráveis da cadeia produtiva possam ser fortalecidos ou criados, buscando atrair indústrias interessadas especificamente no conhecimento produzido nestas regiōes.

Uma segunda observação, diz respeito ao peso da microrregião de São Paulo. A presença e a posição de destaque em quase todos os clusters, com exceção de armamento e aeronaves, confere a região um papel crucial na economia nacional, como já era esperado, e na criação de oportunidades tecnológicas, como está sendo proposto.

Nesta mesma linha, a microrregião do Rio de Janeiro destaca-se das demais, sobretudo na produção científica, ao lado de São Paulo e Campinas. Aparece também em posição privilegiada no cluster 4 (ciências médicas e setores relacionados). A posição desta região é destacada também nos demais agrupamentos.

Figura 5. Dendograma utilizando cluster 5 -Instrumentos Óticos (Quadro 1).

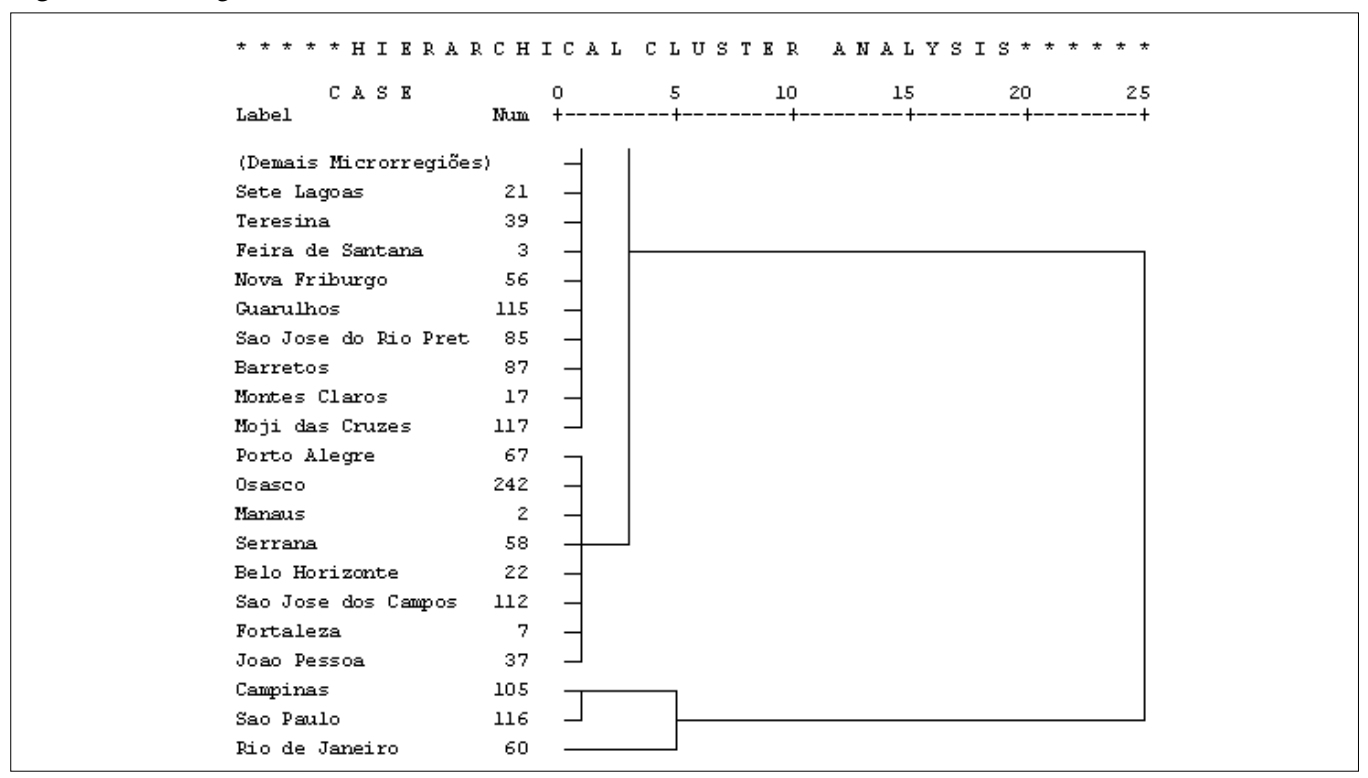

Fonte: Saída do pacote SPSS versão 10. 
Figura 6. Dendograma utilizando cluster 6-Máquinas-ferramenta (Quadro 1).

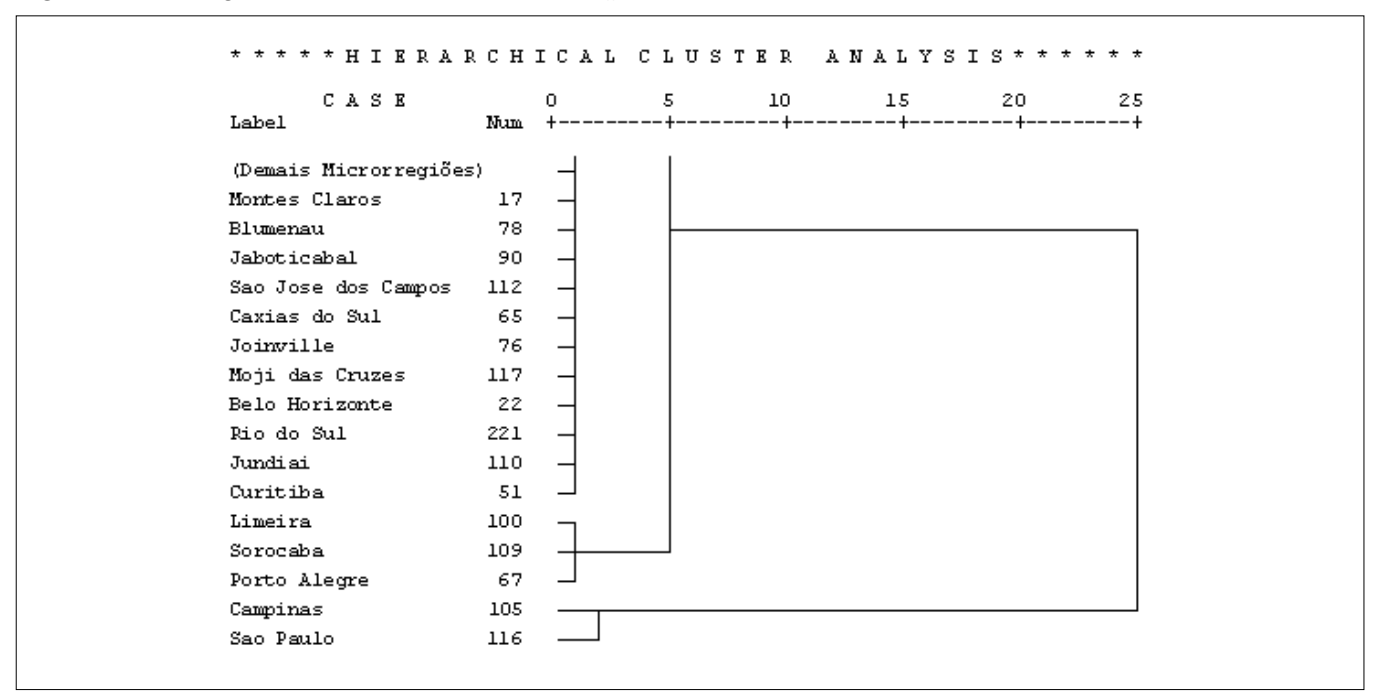

Fonte: Saída do pacote SPSS versão 10.

Tabela 6. Distribuição dos empregados do setor de maquias-ferramenta por microrregião do Brasil 2000, em porcentagem.

\begin{tabular}{|c|c|c|}
\hline UF & Micro-rregião & Máquinas-ferramenta \\
\hline SP & Campinas & 18.42 \\
\hline SP & São Paulo & 24.14 \\
\hline & SOMA & 42.56 \\
\hline RS & Porto Alegre & 11.06 \\
\hline SP & Limeira & 6.53 \\
\hline SP & Sorocaba & 2.93 \\
\hline & SOMA & 25.53 \\
\hline
\end{tabular}

Fonte: RAIS (2000).

Devemos destacar também a microrregião de São Carlos que aparece apenas no cluster 1 , referente às áreas de conhecimento. Apesar disto apresenta taxas de crescimento diferenciadas para vários setores que tomam as disciplinas para as quais a microrregião se destaca como sendo fundamental. Neste sentido, deve-se atentar para o fato de que, embora algumas regióes não apresentem atualmente uma estrutura industrial capaz de evidenciar uma lógica de localização que destaque a produção científica, estas mesmas podem estar experimentando alterações profundas de sua estrutura produtiva que virão a modificar esta interação em futuro próximo ${ }^{6}$.

\footnotetext{
${ }^{6}$ Uma próxima etapa da pesquisa prevê a utilização do Método Shift-Share de decomposição de taxas de crescimento para avaliar este argumento para todas as microrregiōes brasileiras.
}

Por sua vez, a maior desconcentração relativa das atividades tecnológicas no Estado de São Paulo, encontrada por Albuquerque et al. (2001) é verificada na presença de outras microrregióes do estado nos clusters apresentados, enquanto para as outras Unidades da Federação existe uma concentração nas regiōes metropolitanas.

O problema de desconexão entre as unidades de análise, mencionado anteriormente, não é totalmente resolvido pela adoção de microrregiōes, ao invés de municípios como em Albuquerque et al. (2001). Contudo, pode-se argumentar que, mesmo não estando reunidos em clusters, devido à alta concentração espacial de algumas indústrias e disciplinas, os setores industriais e as áreas do conhecimento apresentam uma lógica na distribuição espacial. Isto pode ser visto na repetição de algumas regiōes em mais de um cluster. Um exemplo disso pode ser dado pela microrregião de São José dos Campos, com 7, 37\% 
Figura 7. Dendograma utilizando cluster 7 -Automóveis e eletrônico básico (Quadro 1).

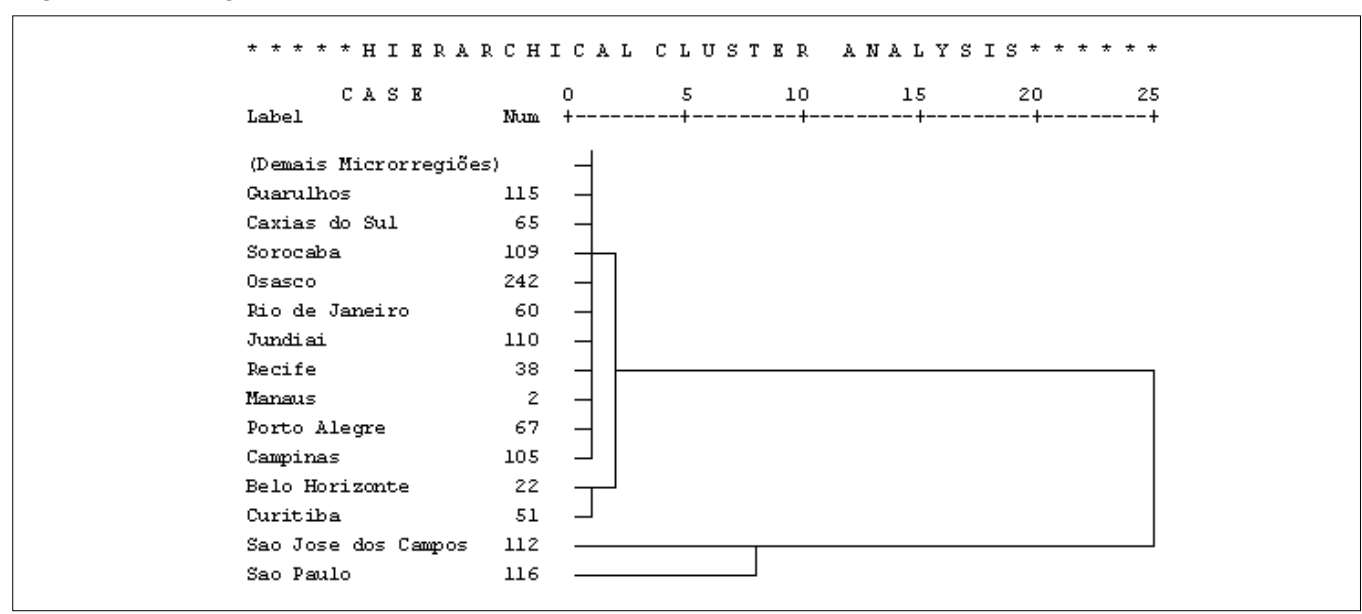

Fonte: Saída do pacote SPSS versão 10.

Figura 8. Dendograma utilizando cluster 8 -Computadores (Quadro 1).

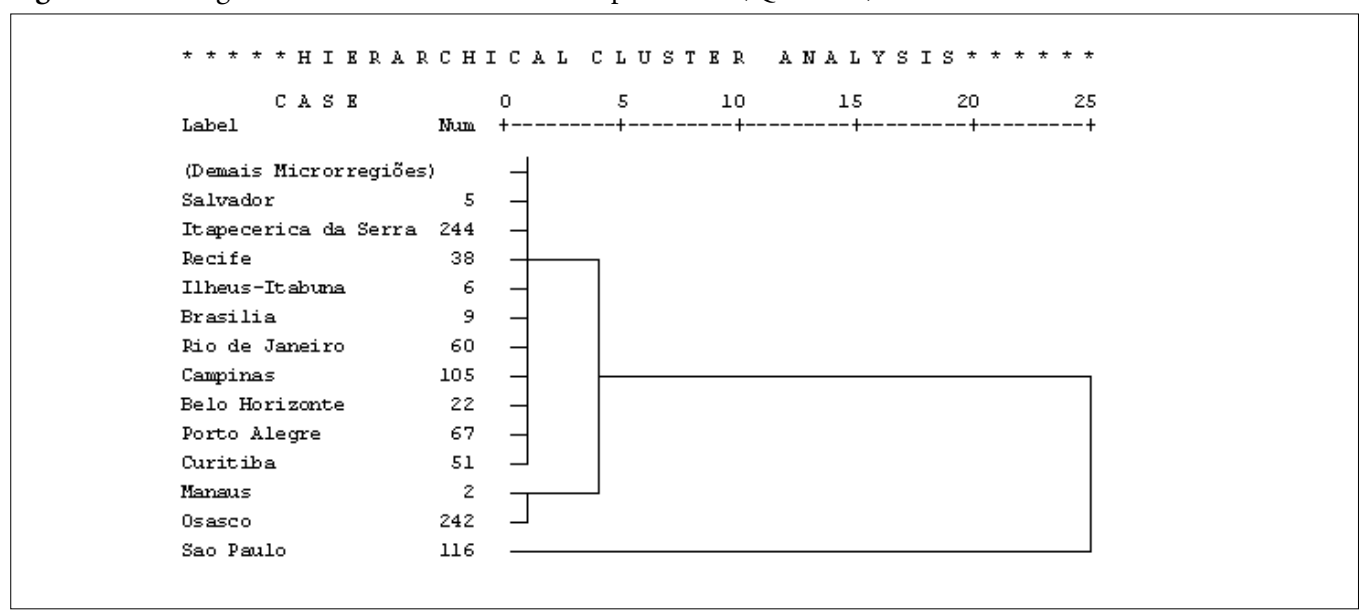

Fonte: Saída do pacote SPSS versão 10.

dos artigos de metalurgia e ciência de materiais (Tabela 3) e 85,30\% dos empregados da indústria de aeronaves (Tabela 11). Além deste, há os exemplos mais claros como São Paulo, Rio de Janeiro e Campinas, e outros menos, como Belo Horizonte.

No caso específico das microrregióes mineiras, a ocorrência apenas da região de Belo Horizonte, mesmo assim em nível inferior às de São Paulo e Rio de Janeiro, pode ser entendido pelo estágio de desenvolvimento do seu sistema de inovação e suas atividades tecnológicas, descritas em Silva et al.
(2000). A especialização do estado em setores de baixa tecnologia, segundo a classificação da Organização Econômica de Cooperação para o Desenvolvimento (OECD), e baixo índice de aproveitamento de oportunidades tecnológicas, revelam a necessidade de se pensar em uma reorientação do setor produtivo, a fim de melhorar a sua condição tecnológica. Para tanto, deve-se pensar na criação e desconcentração das atividades científicas e industriais do estado, criando novas oportunidades e aproveitando melhor as já existentes. 
Tabela 7. Distribuição dos empregados dos setores de automóveis e material eletrônico por microrregião do Brasil, 2000, em porcentagem.

\begin{tabular}{|c|c|c|c|}
\hline UF & Microrregião & Automóveis & Material eletrônico \\
\hline SP & São Paulo & 47,17 & 25,90 \\
\hline SP & São Jose dos Campos & 20,74 & 19,52 \\
\hline & SOMA & 67,91 & 45,42 \\
\hline MG & Belo Horizonte & 13,69 & 2,64 \\
\hline PR & Curitiba & 9,12 & 2,70 \\
\hline & SOMA & 22,82 & 5,34 \\
\hline
\end{tabular}

Fonte: RAIS (2000), elaboração própria.

Tabela 8. Distribuição dos empregados do setor de computadores por microrregião do Brasil, 2000, em porcentagem.

\begin{tabular}{|c|c|c|}
\hline UF & Microrregião & Computadores \\
\hline SP & São Paulo & 33,39 \\
\hline AM & Manaus & 12,92 \\
\hline SP & Osasco & 12,15 \\
\hline RJ & Rio de Janeiro & 7,04 \\
\hline SP & Campinas & 5,35 \\
\hline RS & Porto Alegre & 4,75 \\
\hline MG & Belo Horizonte & 4,16 \\
\hline PR & Curitiba & \\
\hline
\end{tabular}

Fonte: RAIS (2000), elaboração própria.

Figura 9. Dendograma utilizando cluster 9-Armamento pesado e aeronaves (Quadro 1).

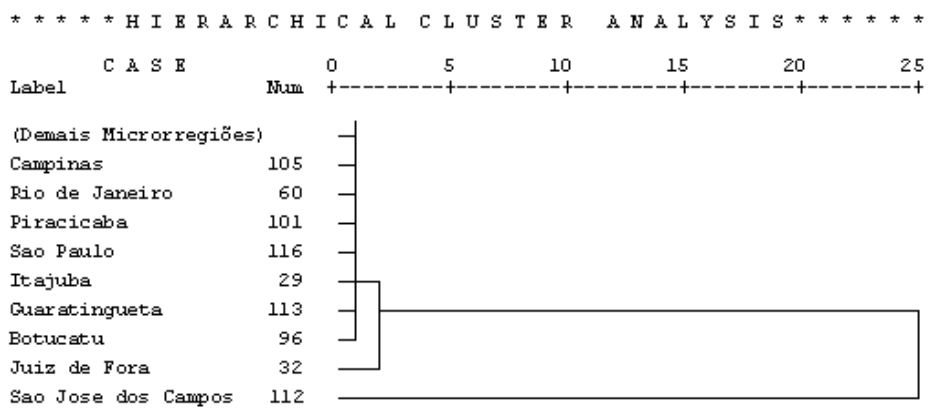

Fonte: Saída do pacote SPSS versão 10.

Tabela 9. Distribuição dos empregados dos setores de armamento pesado e aeronaves, por microrregião do Brasil, 2000, em porcentagem.

\begin{tabular}{|c|c|c|c|}
\hline UF & Microrregião & Armamento Pesado & Aeronaves \\
\hline SP & São Jose dos Campos & 66,049 & 85,30 \\
\hline MG & Juiz de Fora & 26,29 & 0.000 \\
\hline
\end{tabular}

Fonte: RAIS (2000), elaboração própria.

\section{Considerações finais}

Este trabalho abordou a existência de oportunidades tecnológicas para as microrregiōes brasileiras. Mesmo sendo a análise realizada aqui de caráter preliminar, algumas conclusóes podem ser relacionadas: (a) interesse de certos setores industriais em áreas do conhecimento específicas confere uma lógica espacial à distribuição destas atividades; (b) a concentração das atividades científicas e industriais na região $\mathrm{Su}$ deste, principalmente no Estado de São Paulo, é refletida na presença de oportunidades tecnológicas; (c) há um potencial de criação de oportunidades tecnológicas a ser desenvolvida pelas microrregiôes, em especial para aquelas que ainda não conseguiram aproveitar a base científica de seu entorno, internalizando fases da cadeia produtiva. 
Mapa 3. Microrregiōes e número de clusters a que pertencem.

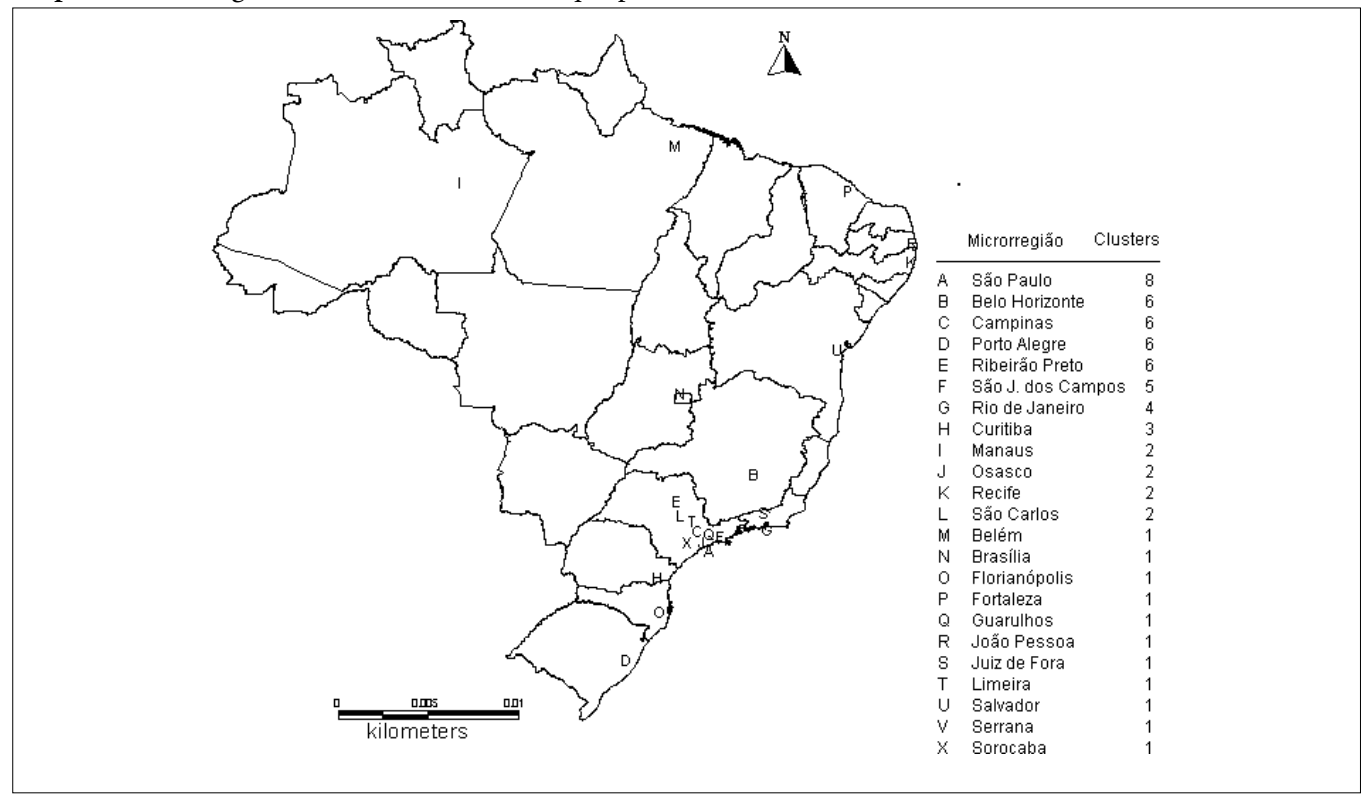

Fonte: ISI (1999); RAIS (2000), elaboração própria.

Também alguns pontos para desenvolvimentos posteriores podem ser sugeridos: (a) em primeiro lugar, deve-se buscar medir a eficiência das atividades tecnológicas nas microrregiōes, através de estatísticas de patentes, de acordo com a interação entre ciência e atividade industrial sugerida aqui; (b) utilizar estatísticas de patentes, discriminadas por classe internacional da patente e setor de atividade da titular, no sentido de separar as fontes de oportunidades tecnológicas; (c) decompor a dinâmica das taxas de crescimento microrregionais dos setores industriais no país, procurando avaliar as mudanças da estrutura produtiva em direção a uma maior interação entre a base tecnológica e a base científica em termos locais e regionais.

\section{Referências bibliográficas}

Albuquerque, E. da M., R. Simões, A. Baessa, B. Campolina e L. Silva (2001). "A distribuição espacial da produção científica e tecnológica brasileira: uma descrição de estatísticas de produção local de patentes e artigos científicos". Anais XXIX Encontro Nacional de Economia. Salvador: ANPEC.

Audretsch, D. \& M. Feldman (1996). "R\&D spillovers and the geography of innovation and production". American Economic Review, 86, 3. Diniz, C. C. (1994). "Polygonized development in Brazil: neither decentralization nor continued polarization". International Journal of Urban and Regional Research, 18, 2.

(2001). "O papel das inovações e das instituiçōes no desenvolvimento local”. Anais XXIX Encontro Nacional de Economia. Salvador: ANPEC.

Diniz, C. C. \& M. A. C. Afonso (1998). "Reestructuración económica e impacto regional: el nuevo mapa de la industria brasileña. Globalización y territorio - impactosy perspectivas. Santiago: Fondo de Cultura Económica.

Diniz, C. C. \& E. Gonçalves (2000). "Possibilidades e tendência locacional da indústria do conhecimento no Brasil". Anais XXVIII Encontro Nacional de Economia. Campinas: ANPEC.

Diniz, C. C. \& M. B. Lemos (1997). “Technology and economic development: suitability of the institutional system of Minas Gerais”. Physics and industrial development: bridging the Gap. Cingapura: World Scientific Publishing Co.

Institute of Scientific Information (1999). www.webofscience.fapesp.br

www.webofscience.fapesp.br 
Jaffe, A. B., M. Trajtenberg e R. Henderson (1993). "Geographical localization of knowledge spillovers as evidenced by patents citations". QJE, $108,3$.

Klevorick, A., R. Levin, R. Nelson eS. Winter (1995). "On the sources and significance of interindustry differences in technological opportunities". Research Policy, $24,2$.

Mainly, F. J. B. (1986). Multivariate statistical methods. London: Academic Press.

Narin, F., K. S. Hamilton e D. Olivastro (1997). “The increasing linkage between U.S. technology and public science". Research Policy, $26,3$.

Pavitt, K. (1984). "Sectorial patterns of technical change”. Research policy, 13.
Powell, W. W., K. W. Koput, J. I. Bowie e L. SmithDoerr (2002). "The spatial clustering of science and capital: accounting for biotech firm-venture capital relationships". Regional Studies, 36, 3.

RAIS (2000). Relação anual de informaçōes sociais. RAIS TRAB/RAISTSTB. Brasília: Ministério do Trabalho e do Emprego (CD ROM).

Rosenberg, N. (1982). Inside the black box: technology and economics. Cambridge: Cambridge University Press.

Silva, L., M. Rapini, R. Fernandes e A. P. Verona (2000). Estatísticas de patentes e atividades tecnológicas em Minas Gerais. Belo Horizonte: CEDEPLAR-UFMG.

\footnotetext{
Pontificia Universidad Católica de Chile,

Facultad de Arquitectura, Diseño y Estudios Urbanos,

Instituto de Estudios Urbanos y Territoriales
}

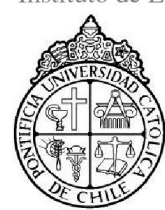

Magíster en Asentamientos Humanos y Medio Ambiente

Territorio, Desarrollo Sustentable y Calidad de Vida

$\begin{array}{lllllllllll}\mathbf{P} & \mathbf{o} & \mathbf{s} & \mathbf{t} & \mathbf{u} & \mathbf{l} & \mathbf{a} & \mathbf{n} & \mathbf{t} & \mathbf{e} & \mathbf{s}\end{array}$

Podrán ingresar al programa postulantes nacionales o extranjeros que posean un grado académico de licenciado o un título profesional.

La admisión está orientada a graduados en las áreas de Administración, Agronomía, Arquitectura, Biología, Derecho, Economía, Geografia, Ingeniería y Sociología. Los postulantes de otras disciplinas podrán ser admitidos con la aprobación del Comité del Programa.

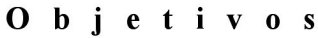

Tiene como objetivo específico el estudio sistemático e interdisciplinario de los procesos de organización del territorio en su dinámica ambiental, a nivel nacional, regional y local. En este contexto se privilegia el estudio de los diversos tipos de asentamientos humanos, urbanos y rurales, considerando las relaciones entre su distribución territorial y el uso de los recursos naturales, y sus formas de interacción, atendiendo al mejoramiento del medio ambiente social y físico.

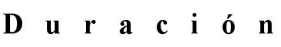

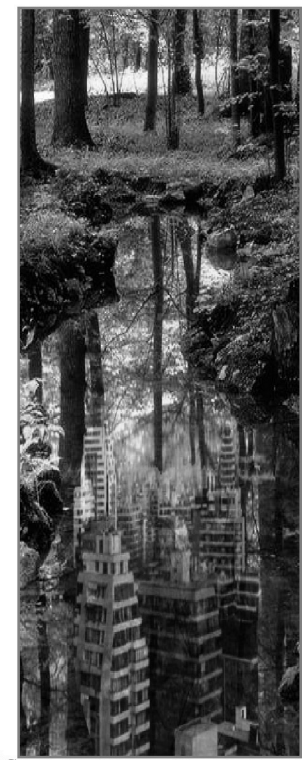

3 semestres académicos incluido período de tesis

Marzo 2005-Julio 2006

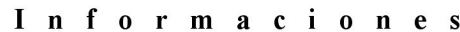

Teléfonos: (56-2) 686 5551, (56-2)686-5511

E-mail: ptorrena@puc.cl

Campus Lo Contador, El Comendador 1916, Providencia - Santiago - Chile 